\title{
Comparative Ultrastructural Study of Rabbit Müller Cells In Vitro and In Situ
}

\author{
MASATO WAKAKURA and WALLACE S. FOULDS \\ Glasgow
}

\begin{abstract}
Summary
The ultrastructural appearance of cultured rabbit glial cells (putative Müller cells) has been compared with that of rabbit Müller cells in situ. Electron microscopy disclosed that the cultured cells had a basement membrane comparable to the inner limiting membrane of the retina and that villous processes adjacent to zonulae adherentes were reminiscent of fibre baskets and the outer limiting membrane. Cultured cells showed apico-basal polarisation in specimens from early passages. It was noted however that cultured cells showed a number of features which were different from normal Müller cells in situ. These included prominent rough endoplasmic reticulum, sparse smooth endoplasmic reticulum and relatively electron lucent cytoplasmic matrices. These findings resembled the appearances found in proliferating Müller cells in the human eye. The ultrastructural differences noted in the cultured Müller cells suggest that the cultured cells are in an active form.
\end{abstract}

The use of cell cultures in biological experiments is often desirable and has several advantages. Pure cellular populations can be examined, the cellular environment can be easily controlled and animal experiments can be limited or avoided. It has been suggested that the rabbit retina is a good source for in vitro studies of neural tissues as in vitro incubation allows both ultrastructural and electrophysiological preservation. ${ }^{1-2}$ Müller cells are the predominant glial cells in the retina and play an important role not only in normal but also in pathological conditions. ${ }^{3}$ Pure Müller cells cultured from adult retina have become available as a result of the recent introduction of a suitable technique..$^{4,5}$ However, ultrastructural comparisons between Müller cells in vitro and those in situ have not been reported. It is important to determine that morphological characteristics are retained by cells in culture before such cultures can be deemed representative of Müller cells in situ.
Müller cells have an important role in the response to retinal damage from disease or injury and their possible implication in such conditions as epiretinal membrane formation, surface wrinkling retinopathy and proliferative vitreo-retinopathy has recently been the subject of study and speculation. ${ }^{6-9}$

The aim of this study is to compare the ultrastructural features of Müller cells in vitro with those demonstrated by Müller cells in situ.

\section{Materials and Methods}

Animals and Cell Culture

Eyes were obtained from adult albino and pigmented rabbits of both sexes. The anterior portions of the eyes were incised circumferentially about $2 \mathrm{~mm}$ posterior to the limbus. After removal of the vitreous body the posterior eye cup was immersed in either a fixative or in phosphate buffered saline (PBS, $\mathrm{pH}$ 7.2).

Posterior eye cups in fixative were proces-

Correspondence to: Professor W. S. Foulds, Department of Ophthalmology, Tennent Institute of Ophthalmology; Western Infirmary, Glasgow G11 6NT. 
sed for immunofluorescence or transmission electron microscopy.

For Müller cell cultures the PBS immersed eye cups were used. The retina in the posterior eye cup was gently detached by a stream of PBS and then placed in a dish with serum-free Glasgow minimum essential medium (GMEM, Gibco). Cell culture was performed using a minor modification ${ }^{10}$ of the method described by Burke et al (1984). ${ }^{4}$ In short, small portions of retina were cut from an avascular and non-medullated area and were suspended in GMEM supplemented by 10 per cent fetal calf serum, $2 \mathrm{mM}$ L-glutamine and antibiotic, antimycotic solution and incubated in five per cent $\mathrm{CO}_{2} /$ air at $36.5^{\circ} \mathrm{C}$. After 6-7 days the suspended tissue was re-suspended in fresh GMEM and sub-cultured in either 24 well plates or on $13 \mathrm{~mm}$ glass cover slips in each well precoated with human fibronectin $(25 \mathrm{mg} / \mathrm{ml})$ (Gibco). Thereafter the culture was passaged every 4-10 days. For the present study, cultures from the second to fifth passage were employed.

\section{Electron Microscopy}

For in vivo studies, portions of the posterior eye cups were processed conventionally for electron microscopy using the same routine as used for the preparation of cultured cells for microscopy, namely, specimens were fixed in two per cent glutaraldehyde with $0.1 \mathrm{M}$ cacodylate buffer at $\mathrm{pH}$ 7.2. Specimens were postfixed for one hour in one per cent osmium tetroxide and dehydrated through graded concentrations of ethanol to absolute alcohol. Absolute alcohol was replaced by propyrene oxide, and monolayers of cultured cells were detached from the plates using a needle. All specimens were embedded in Araldite. Ultrathin sections were made with an ultramicrotone (LKB 8800 III) and stained with uranyl acetate and lead citrate and examined with a Philips 301 transmission electron microscope.

\section{Results}

\section{Transmission Electron Microscopy}

Rabbit Retinal Tissue

On electron microscopy the appearance of the Müller cells was essentially similar to that reported in previous studies. ${ }^{11,12}$ The cytoplasmic matrices were generally electron dense. In the inner vitread portions, the cells contained abundant smooth endoplasmic reticulum and microfilaments (Fig. 1a).The basement membrane was identifiable in the inner limiting membrane if it was well-preserved. In the inner plexiform layer, the Müller cell processes contained numerous microfilaments and microtubules (Fig. 1b). In the nucleated middle portion, the cells contained a number of smooth endoplasmic reticula and some micro-filaments. Rough endoplasmic reticulum was only seen at this site. Nuclei were frequently found to have a nucleolus (Fig. 1c). The cytoplasm of the outer portions of the cells showed numerous mitochondria, an occasional golgi complex and microtubules. The outer limiting membrane consisted of the zonulae adherentes and fibre baskets were formed in the layer of the inner segments (Fig. 1d).

\section{Cultured Cells}

The monolayers which were obtained from the second and third passaged cultures often showed apico-basal polarisation (Fig. 2), but after the fourth passage this was unusual (Fig. 3c). The apico-basal polarisation when present resulted in cells which showed a smooth surface identifiably equivalent to the inner (vitread) component of the in situ Müller cell and a diametrically opposed surface with features reminiscent of the external limiting membrane (ELM). Basement membrane was occasionally seen on the smooth surface of the cells (Fig. 3a). In the periphery of the cells, packed microtubules could be seen (Fig. 3b). The nucleus often had a prominent nucleolus (Fig. 3c). Smooth endoplasmic reticulum was only rarely seen while rough endoplasmic reticula showed well-developed profiles throughout the cells (Figs. 2, 3a and 3c). The cell membrane opposite to the smooth surface of the cells demonstrated zonulae adherentes and villous processes (Figs. 2 and 3d). These structures were reminiscent of the ELM and fibre baskets although the villi were smaller in size than those seen in vivo. 


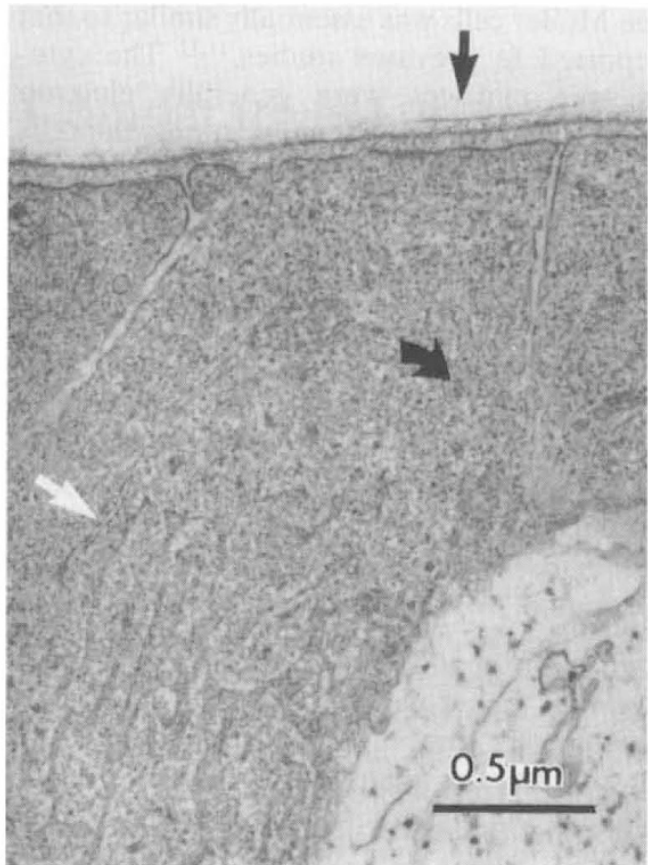

a

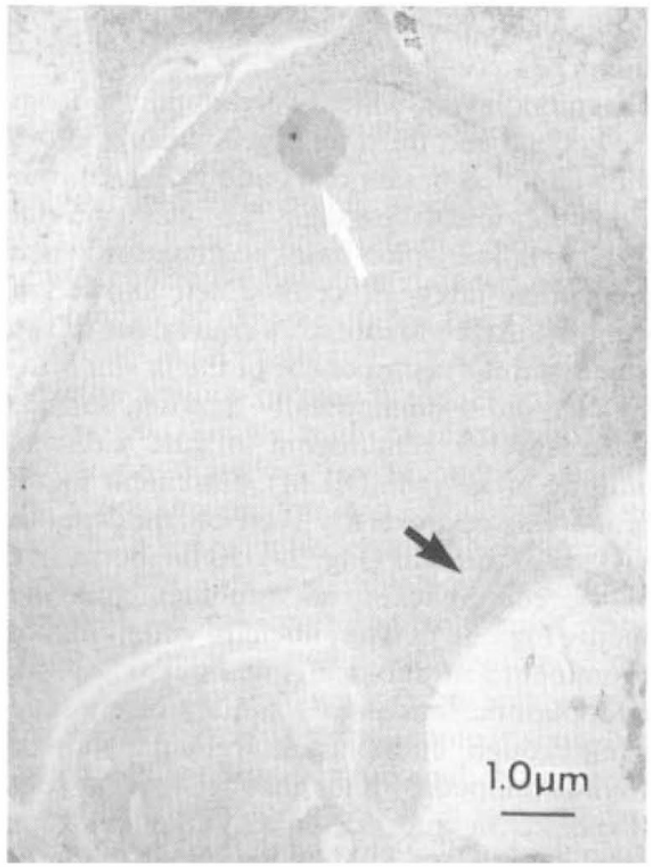

c

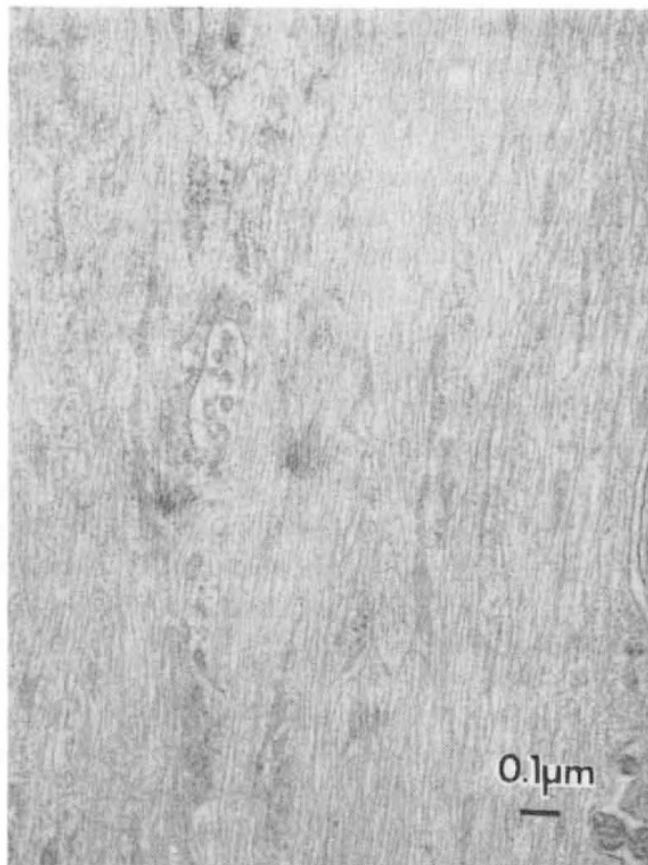

b

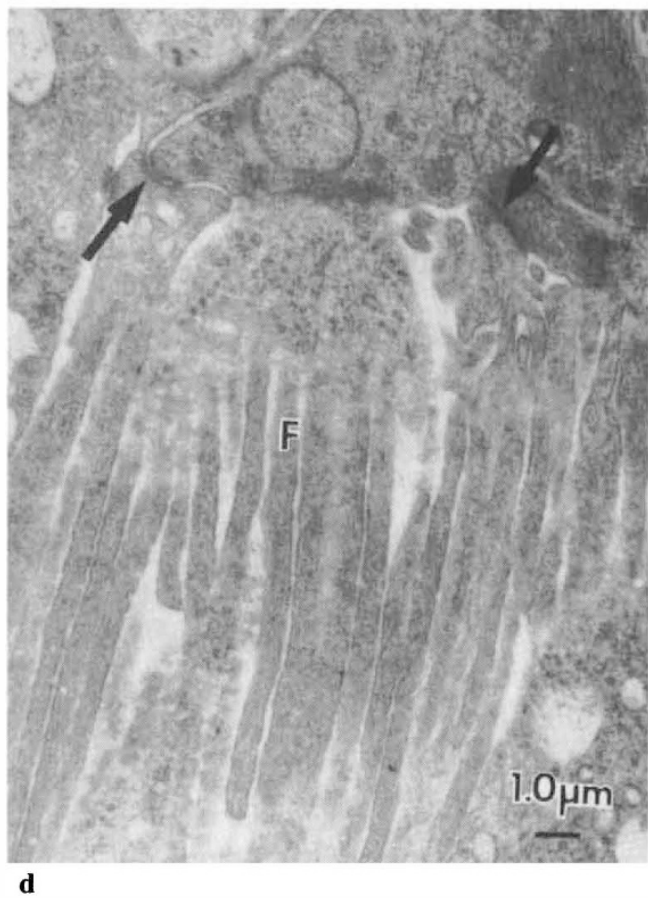

Fig. 1. Electron micrograph of rabbit Müller cells in vivo. (a) Abundant smooth endoplasmic (white arrow) reticula and microfilaments (curved arrow) in a cell process. Black arrow indicates the inner limiting membrane with the basement membrane. (b) Müller cell process from the inner plexiform layer. Note numerous microfilaments and microtubules. (c) The nuclear portion of a Müller cell. Black arrow indicates rough endoplasmic reticulum. The nucleus has a nucleolus (white arrow). (d) The outermost portion of a Müller cell. The outer limiting membrane is composed of the zonulae adherentes (arrows). Note the formation of fibre baskets $(F)$. 


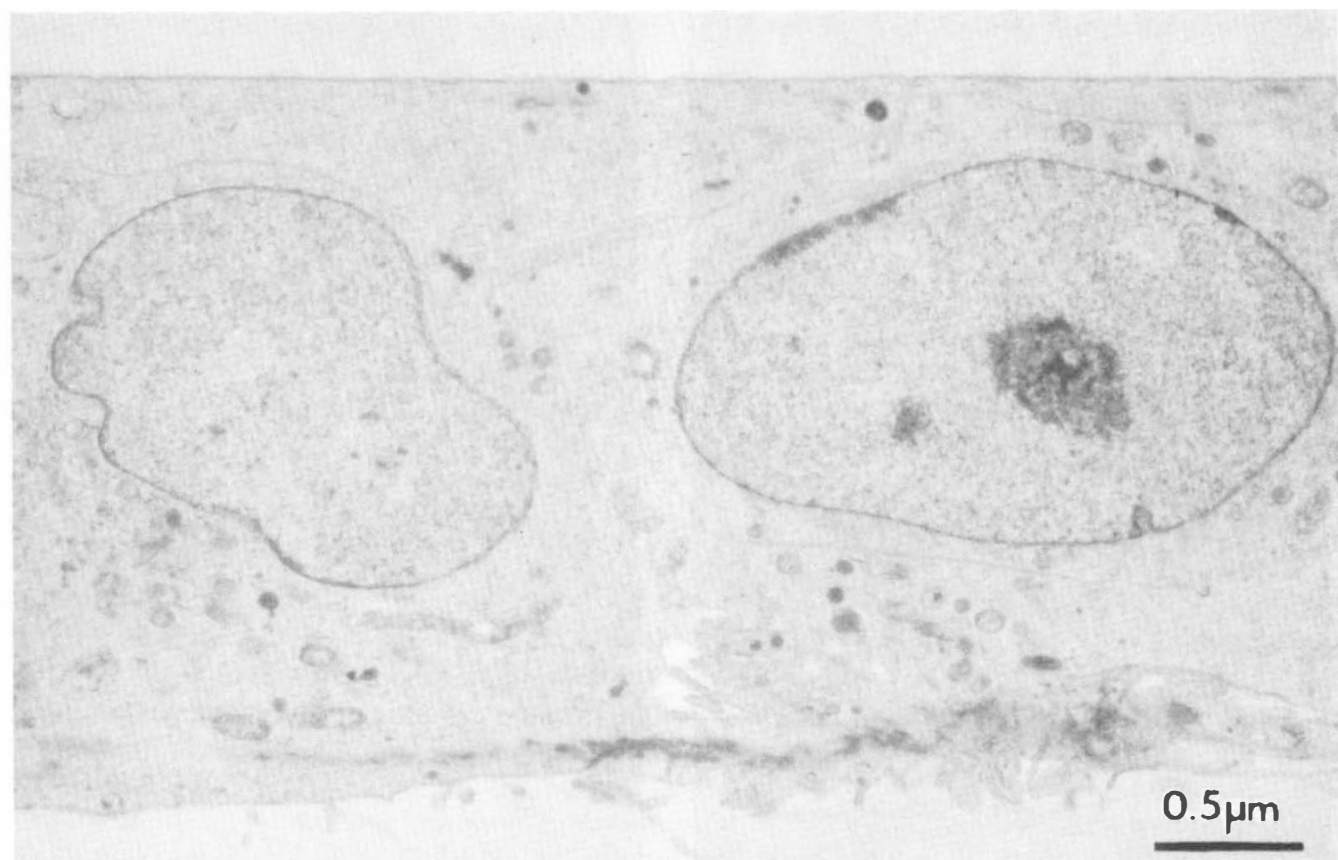

Fig. 2. Electron micrograph of cultured Müller cells in second passage.

\section{Discussion}

The method used to prepare Müller cell cultures was designed to avoid contamination with astrocytes by selecting explants from a non-medullated avascular area of rabbit retina which has been shown by immunohistochemistry not to contain astrocytes. ${ }^{13}$ In other studies which we have carried out ${ }^{10}$ we have shown that the putative Müller cell cultures not only expressed specific glial cell markers $^{14,15}$ (GFAP, vimentin, S100 protein), but additionally were positive for carbonic anhydrase isozyme $\mathrm{C}$ which is a specific marker for Müller cells and is not expressed by astrocytes. ${ }^{16} \mathrm{We}$ are confident therefore that the cultured cells were indeed of Müller cell origin.

It was found that cultured Müller cells possessed many ultrastructural features in common with Müller cells in vivo, for example, the presence of basement membrane resembling the internal limiting membrane and villous processes adjacent to the zonulae adherentes reminiscent of the fibre baskets and the external limiting membrane. Promi- nent nucleoli, numerous intermediate filaments and microtubules were also common findings. A striking feature was the presence of apico-basal polarisation in second and third passaged cultures. This feature was lost in the fourth and subsequent passages. This finding suggests that early passaged cells may be more appropriately used as representative of Müller cells in vivo than cells from later passages.

On the other hand, it was noted that cultured cells had several ultrastructural features which differed from Müller cells in vivo. The cytoplasm of the cultured cells had light matrices, a finding which has been previously reported. ${ }^{1}$ This is unlikely to be due to poor fixation as penetrance of the fixative, if anything, would be better in the case of monolayers of cultured cells than for intact retina. Moreover, rough endoplasmic reticulum was abundant whereas smooth endoplasmic reticulum was sparse. The appearances resembled those previously described in proliferating Müller cells. ${ }^{9}$

In the human and most other mam- 


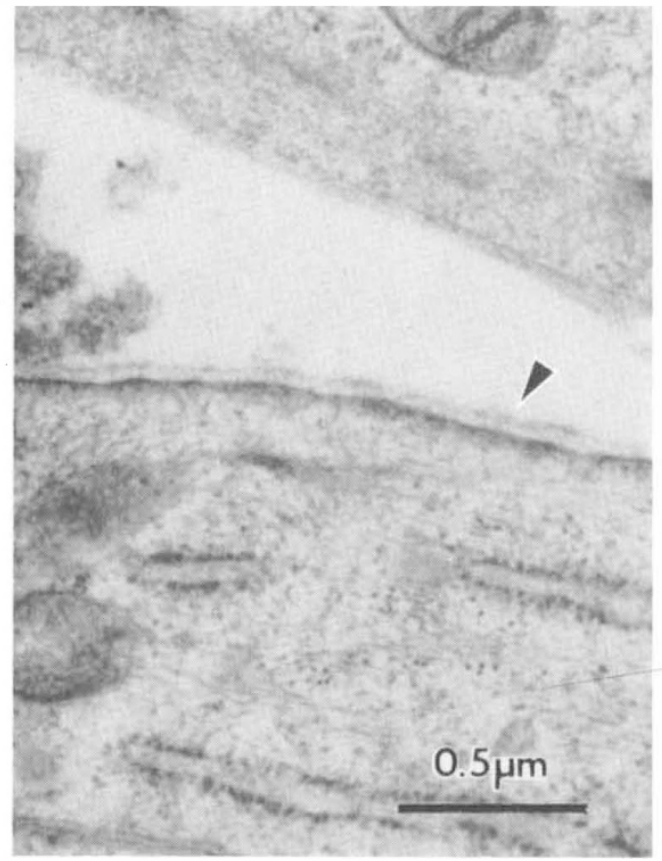

a

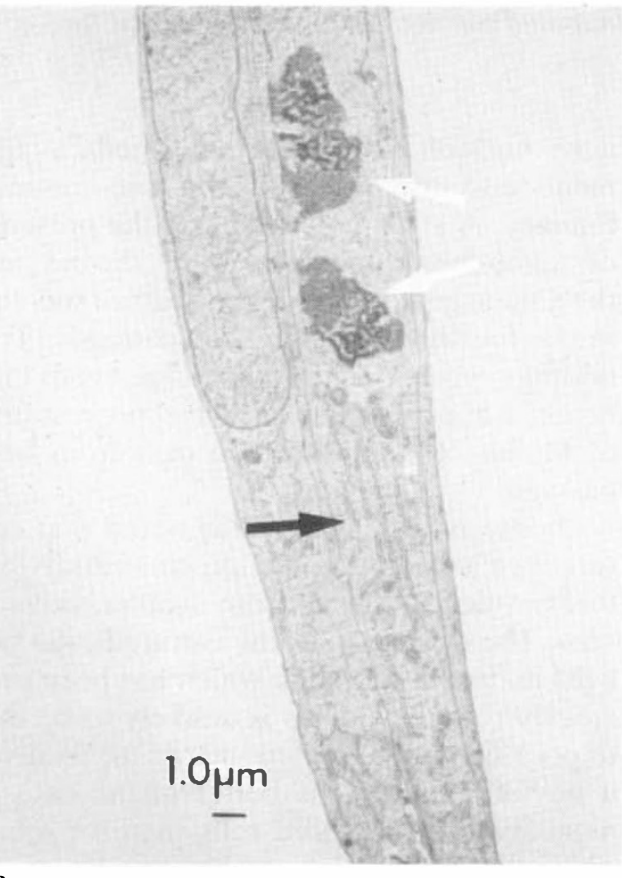

c

Fig. 3. Electron micrographs of cultured cells. (a) Smooth surface of the cell. Triangle indicates basement membrane like material resembling Figure 1(a). (b) Periphery of a cell. Note packed microfilaments and microtubules comparable to Figure 1(b). (c) Cells from the fifth passage. Note rough endoplasmic reticula (black arrow) with well developed profiles and a prominent nucleolus (white arrows). The cells do not show clear apico-basal polarisation. (d) The villous side of the cell, the zonulae adherentes (arrow) and villous processes (curved arrow) are reminiscent of the outer limiting membrane and fibre baskets (see Fig. 1d).

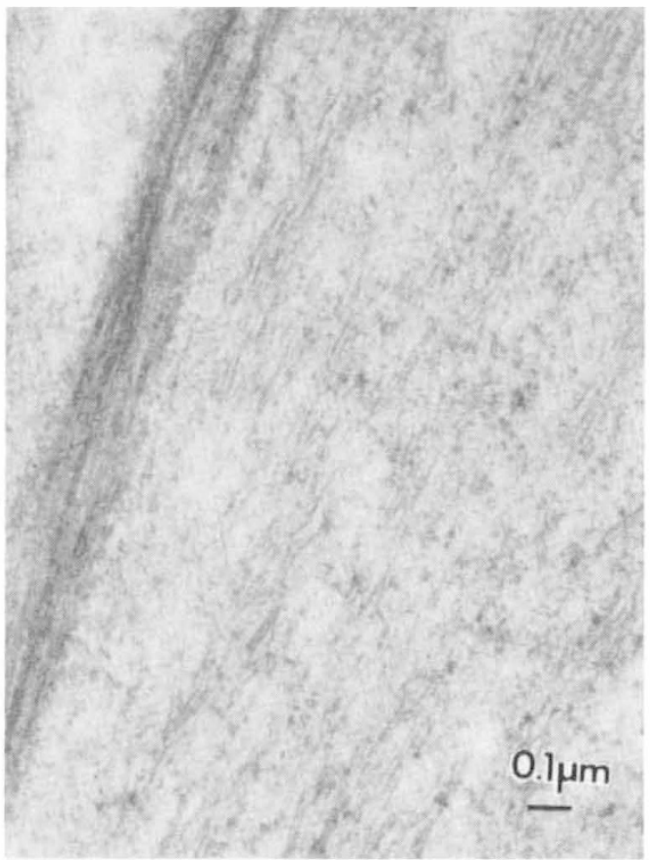

b

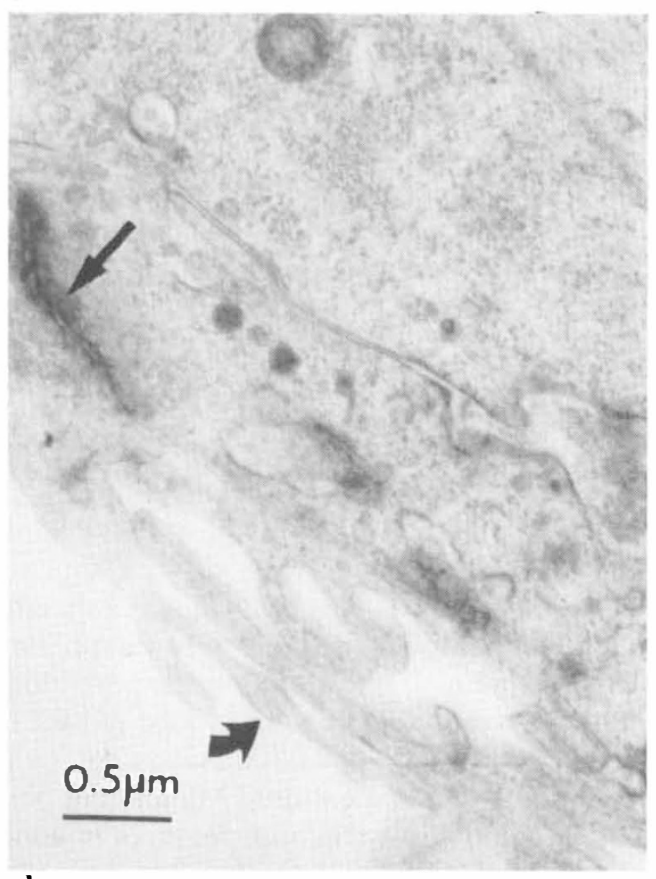

d 
mals, ${ }^{6,7,15,16}$ GFAP is not detectable in Müller cells in situ. It is known, however, that GFAP expression develops in reactive states. ${ }^{6,14}$ GFAP positive cells are present in tissues obtained from epiretinal membranes $^{7,8}$ and in proliferating Müller cells from massive gliosis. ${ }^{9}$ Our cultured Müller cells expressed GFAP. ${ }^{10}$ The change from GFAP negativity in situ to GFAP positivity in vitro may be comparable to the transformation of normal Müller cells to reactive Müller cells. Thus cultured Müller cells may be considered active forms retaining most of the morphological characteristics of the in situ condition.

Early passaged cells may reasonably be used to study the characteristics of in situ Müller cells while later passaged cells may be useful to study the changes accompanying Müller cell activation and proliferation.

The authors would like to thank Professor W. R. Lee for his advice and Mrs. S. A. Cameron for her technical assistance. The work has been supported by the Wellcome Trust (MW) Grant No 16472/1.4 and has in part been presented at a meeting of the European Club for Ophthalmic Fine Structure (September 1987, Paris).

\section{References}

${ }^{1}$ Hansson HA: Müller's neuroglial cells in cultures of rabbit retina Exp Eye Res: 1971; 11: 105-10.

2 Webster $\mathrm{H}$ deF and Ames A 3rd: Reversible and irreversible changes in the fine structure of nervous tissue during oxygen and glucose deprivation. J Cell Biol, 1965; 26: 885-909.

${ }^{3}$ Sigelman J and Ozanics V: Retina. In: Biomedical Foundation of Ophthalmology, ed. Duane TD and Jaeger EA. Vol 1, chapter 19 pp 1-66 1985, Harper and Row, Philadelphia.

${ }^{4}$ Burke JM and Foster SJ: Culture of adult rabbit retinal glial cells: methods and cellular origin of explant outgrowth. Curr Eye Res, 1984; 3: 1169-78.

${ }^{5}$ Trachtenberg $\mathbf{M}$ and Packey DJ: Rapid isolation of mammalian Müller cells. Brain Res, 1983; 261: 43-52.
${ }^{6}$ Bignami A and Dahl D: The radial glia of Müller in the rat retina and their response to injury. An immunofluorescence study with antibodies to the glial fibrillary acidic (GFA) protein. Exp Eye Res, 1979; 28: 63-9.

${ }^{7}$ Hiscott PS, Grierson I, Trombetta CJ, Rahi AHS, Marshall J, McLeod D: Retinal and epiretinal glia - an immunocytochemical study. Br J Ophthalmol, 1984; 68: 698-707.

${ }^{8}$ Yamashita H, Hori S, Kitano S, Masuda K: Glial cells in culture of pre-retinal membrane of proliferative vitreo-retinopathy. Jpn $J$ Ophthalmol, 1985; 29: 42-53.

${ }^{9}$ Nork TM, Chobrial MW, Peyman GA, Tso MOM: Massive retinal gliosis. A reactive proliferation of Muller cells. Arch Ophthalmol, 1986; 104: 1383-9.

${ }_{10}$ Wakakura $\mathrm{M}$ and Foulds WS: Immunocytochemical characteristics of Müller cells cultured from adult rabbit retina. Invest Ophthal Vis Sci, 1988; 29: 892-900.

${ }^{11}$ Magalhaes MM and Coimbra A: The rabbit retina Müller cell. A fine structural and cytochemical study. J Ultrastruct Res, 1972; 39: 310-26.

12 Uga S and Smelser GK: Comparative study of the fine structure of retinal Müller cells in various vertebrates. Invest Ophthalmol Vis Sci, 1973; 12: 434-48.

${ }^{13}$ Schnitzer J: Distribution and immunoreactivity of glia in the retina of the rabbit. J Comp Neurol, 1985; 240: 128.

${ }^{14}$ Molnar ML, Stefansson K, Marton LS, Tripathi RC, Molnar GK: Distribution of S-100 protein and glial fibrillary acidic protein in normal and gliotic human retina. Exp Eye Res: 1984; 38: $27-34$.

${ }^{15}$ Kievela $\mathrm{T}$, Tarkkanen A, Virtanen I: Intermediate filaments in human retina and retinal blastoma. An immunohistochemical study of vimentin, glial fibrillary acidic protein and neurofilaments. Invest Ophthalmol Vis Sci, 1986; 27: 1075-84.

${ }^{16}$ Kumpulainen TD, Dahl D, Korhonen L, Hystrom SHM: Immunolabelling of carbonic anhydrase isozyme $\mathrm{C}$ and glial fibrillary acidic protein in paraffin-embedded tissue sections of human brain and retina. J Histochem Cytochem, 1983; 31: 879-86. 